\title{
Access to Astrophysical Research by Secondary Students
}

\author{
W. Bruce McAdam \\ School of Physics, University of Sydney, NSW 2006, Australia \\ mcadam@physics.usyd.edu.au
}

Received 1999 August 17, accepted 2000 February 24

\begin{abstract}
Astrophysics is an exciting and stimulating branch of physics which generates many new concepts, but giving school students access to these new ideas is difficult. I look at current ways of transferring ideas from Australia's 16 astronomical research centres to keen students across the continent. These include formal courses, science schools, visits to science centres, occasional lectures both within and outside schools, and work experience visits to the research centres. Few of these methods allow interaction between the research astronomer and the student. I outline new ways that we, as professional astronomers, can stimulate students before they reach (or bypass) university. We need an 'information white hole' between our research world and the schools!'
\end{abstract}

Keywords: astronomy education

\section{Introduction}

In early times, science (astrology then) was a profession with an apprentice system in which students learnt from those who observed and planned the research. From the late 19th century, an educational sequence developed (see Table 1) which placed students in schools with slow-changing syllabi, stifling most opportunities for students to experience the newest research methods.

Table 1. The educational sequence

\begin{tabular}{lll}
\hline Phase & Activity & Characteristic \\
\hline Infant & Exploring & Curious \\
Primary & Reading & Curious \\
Secondary & Codified learning & Exam dominated \\
Bachelor & Basic theory & Stifles curiosity \\
MSc and PhD & Research & Exploring \\
Post-doctoral & Research & Excitement \\
\hline
\end{tabular}

This codification of education allows formal exams and curricula to dominate the secondary and early university phases. It is in this period that many students lose interest and turn away from a science career.

However, chance stimulation, incentives and revelations do occur. Most of those who continue with science can recollect a key incident that revealed the excitement and intensity of original investigation and steered them into their career.

I quote two examples. Joan Freeman (1991) records in her autobiography, 58 years later, the impact of the newspaper headline 'Splitting the Atom at the Cavendish Laboratory' (2 May 1932): 'Suddenly I realised that facts laid down in text books were not necessarily inviolate: through scientific research, discoveries could be made which revised or even contradicted existing beliefs.'

For Bryan Gaensler, 1999 Young Australian of the Year: 'The book that started it all was one my parents gave me, simply titled 'Album of Astronomy' ... it drew me in with its incredible descriptions of all the things that had been discovered out there, and, even better, all the things we still didn't know about' (Gaensler1999).

Astronomy continues to find extraordinary things in the Universe, to exploit limits of technology and to challenge theoretical explanation. Almost every year sees new puzzles, crazy concepts and flashes of comprehension. Australian astronomers share these discoveries and, with a world reputation for their research, have both an incentive and a responsibility to stimulate science in all stages of the school system. This is especially true in NSW where $75 \%$ of our professional astronomers work.

The challenge is made specific in the 1993 strategy review of Australian physics: 'In addition to their contribution to Australia's physics research, the universities bear the major responsibility for training new physicists, and for training physics teachers. Basic education in science-including physics-and the stimulation or suppression of interest in these disciplines begin much earlier, in the primary and secondary schools' (National Committee for Physics 1993, p. 10).

\section{Access: The Challenge and Resources}

It is a difficult challenge to give secondary school students an equitable access to current research ideas. Australia has some 2300 high schools widely scattered within eight separate education systems. In NSW there are 814 high schools and what may be taught in themthe science syllabi-have just been rewritten, replacing the 1982 versions (a review every 10-15 years). What is taught depends on options selected by the teacher and the ideas are filtered through the understanding of the teacher. Only about one in six science teachers has a degree with a physics major.

To meet this challenge, the resources in Australian astronomy are considerable. The Anglo-Australian Observatory and the Australia Telescope National Facility together employ 40 professional astronomers. 
One third (14) of Australian universities have 114 astronomers among their staff, and do research with postgraduate students: all 14 universities teach undergraduate astronomy courses-six or seven have firstyear courses. In an average year, the research output is some 500 scientific papers and books (Ekers et al. 1995).

This paper describes ways that the Astronomical Society of Australia (ASA) can assist secondary schools in stimulating curiosity by providing access to the current research and concepts.

\section{Public Access}

Secondary students join with the general public in access to research at the visitors' centres at observatories, planetaria and museums. The number of visitors each year is large; for example the Parkes Observatory reports 60,000, Narrabri 11,000 and the Perth Observatory 6200. It is important, therefore, that these centres display results from current research projects, perhaps by using a selection of poster papers from recent conferences.

My examples above of Freeman (1991) and Gaensler (1999) show that books, newspapers, radio and TV are important media for stimulating students. In each year from 1990-95 Australian astronomers wrote an average of 370 popular articles, books and public lectures, plus some 900 press/radio/TV articles and interviews (Ekers et al. 1995). These channels may feature current research but do not have the same impact as a personal exchange between a student and the research astronomer.

\section{Individual Access}

There are several ways for an individual student to talk with a research astronomer-at lectures, during work experience visits, at science schools, and through computer links with the web and email. ASA members cooperate in all these activities.

- Lecture series to schools, societies or the public, such as the 1999 Women in Physics lecture tour by Professor Jocelyn Bell Burnell (arranged by the Australian Institute of Physics), have the potential to stimulate all science students (perhaps 20,000) in a year. Even a brief personal talk before or after a lecture can lead to email or postal exchanges that continue over a longer time. The National Committee for Physics (1993, p. 50) recommended: 'A register of physicists who are willing to speak in schools, and of laboratories which are willing to host school visits, should be established in order to assist the promotion of education and careers in physics, particularly for women.' This register now exists in Canberra, but there are few astronomers listed.
- Work experience visits (5-10 each year for hospitable departments) give students an insight into the current research process through posters, and attendance at colloquia and staff meetings.

- Science Schools offer a series of lectures and workshops to students over one or two weeks. Meeting with like-minded students is equally valuable. The 30th Professor Harry Messel International Science School was held in July 1999 bringing together 100 students from Australia and 40 from China, Japan, Malaysia, New Zealand, Singapore, United Kingdom and USA. There were three astronomers among the 11 lecturers. Friendships made at such schools last for decades.

- Distance learning courses reach students in remote schools scattered across a state or nation and even across frontiers. In 1992 the Board of Studies in NSW commissioned outlines for nine courses at first-year university level to extend gifted and talented pupils within the NSW education system. Three of these were introduced in 1994-Comparative Literature, Philosophy and Cosmology. Each is a full twounit HSC course taken in one year (Hollow et al. 1994). The Cosmology Distinction Course was studied in 1999 by 32 students through distance learning with Charles Sturt University. Access to astrophysicists is achieved in two ways. First, all students have email contact with each other and with the course coordinator in Bathurst, astronomer David McKinnon, who refers research questions to ASA members on the course committee. Second, all students come together for two 'residentials' in the year. The first is based at Coonabarabran over five days in February, and includes visits to Parkes, Siding Spring, Mopra and Narrabri where astronomers show details of seven major telescopes and talk of new techniques and projects. The second residential is held at Sydney on a weekend in June when four astronomers lecture to, and then discuss their current research with students. This personal contact is an essential part of the Distinction Course and is a major factor in the success of the course.

- As students become familiar with the internet, there is increasing use of Australian and international databases. Almost all astronomy groups in Australia have web servers and post details of their current research programs. This web access is efficient for both astronomer and student. If necessary, further contact is then possible through email.

\section{Conclusion}

In June 1995 the National Committee for Astronomy (1995, p. xviii) of the Australian Academy of Science 
made three recommendations for education with the preamble: Astronomical Education. 'The future of astronomy in the nation depends upon maintaining a strong educational program at primary and secondary school level, at tertiary undergraduate and at postgraduate level. It also depends upon providing a public education which gives the community access to the newest exciting scientific results and achievements of our researchers.'

Recommendation 5 called for a graduate summer school-which we now have each year with the Harley Wood School.

Recommendation 7 asked 'that astronomical institutions should continue to give strong support to public education in astronomy, ... collaborating ... with amateur groups ...'

Recommendation 6 remains a challenge: 'That a strategy for enhancing astronomical education in schools, ... should be formally adopted by the profession. This should be undertaken by the National Committee for Astronomy in consultation with the Astronomical Society of Australia, the Australian Education Council, the Australian Science Teachers' Association and the Schools Council.'

We have made some progress in five years. I recollect that Bart Bok practiced a direct and personal advocacy of the delights of astronomy to politicians, students and public. We should follow his example and, on a national scale, give students access to our research.

\section{Acknowledgments}

I thank the Board of Studies, New South Wales, and the ASA members who have brought astrophysical research to 133 talented students in the Cosmology Distinction Course between 1994 and 2000.

\section{References}

Ekers, R. D., Tzioumis, A. K., Faulkner, D., Mould, J., \& McAdam, W. B. 1995, Report of the NCA Survey Committee, in Australian Astronomy: Beyond 2000, National Board of Employment, Education and Training, 97

Freeman, J. 1991, in A Passion for Physics (Bristol: Adam Hilger), p. 29

Gaensler, B. 1999, Gifted, NSW Association for Gifted and Talented Children, 109, 11

Hollow, R. P., McAdam, W. B., OByrne, J. W., White, G. L., Holmes, R., Webb, J. K., Allen, L. R., Zealey, W. J., \& Hafner, R. 1994, PASA, 11, 39

National Committee for Astronomy 1995, in Australian Astronomy: Beyond 2000, National Board of Employment, Education and Training (Canberra: Aust. Government Publishing Service)

National Committee for Physics 1993, in Physics: A Vision for the Future, National Board of Employment, Education and Training (Canberra: Aust. Government Publishing Service) 